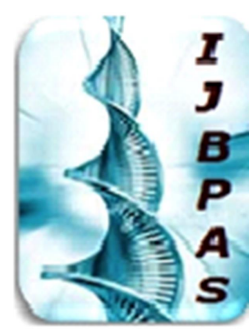

International Journal of Biology, Pharmacy and Allied Sciences (IJBPAS) 'A Bridgs Between Labortory and Qand

Www.jibpas.com

\title{
A READY RECKONER DOCUMENTATION SHEET ON STANDARDIZATION STUDIES ON CALYCOPTERIS FLORIBUNDA (ROXB.) LAM. - AN OVERVIEW
}

\author{
RAJASRI BHARATHI P* AND SHUBASHINI K SRIPATHI \\ Department of Chemistry, Avinashilingam Institute for Home Science and Higher Education \\ for Women, Coimbatore - 641 043, Tamil Nadu, India \\ *Corresponding Author: P. Rajasri Bharathi: E Mail: prsbchemist@gmail.com
}

Received 22 ${ }^{\text {nd }}$ Feb. 2021; Revised $20^{\text {th }}$ April. 2021; Accepted $19^{\text {th }}$ July 2021; Available online $1^{\text {st }}$ Nov. 2021

https://doi.org/10.31032/IJBPAS/2021/10.11.6283

\begin{abstract}
India has the potential to become a major country playing the lead role in the production of standardized, therapeutically efficient ayurvedic formulations. This can only be accomplished if the herbal products are tested and standardized by UV-visible, FTIR, TLC, HPLC, HPTLC, GC-MS, and other methods. The phytochemical profile of a plant is particularly important because it gives documented data on its medicinal potential. The World Health Organization (WHO) emphasizes the significance of qualitative and quantitative approaches for characterizing samples, evaluating biomarkers, chemical markers, and creating finger impression profiles for herbal formulations. The present overview document sheet covers the standardization parameters of the medicinal plant Calycopteris floribunda. This document sheet will aid as a ready reckoner to herbal formulation manufacturers.
\end{abstract}

Keywords: Standardization, WHO, Biomarkers, Herbal formulation, Calycopteris floribunda INTRODUCTION

Traditional medicine is commonly used to treat a variety of human illnesses. The use of herbal medicine can also be traced back to the dawn of time. Traditional medication has grown in popularity around the world due to its effectiveness and curative nature for ailments with less toxicity. Because of their medicinal 
properties, all plants on this planet are deemed valuable [1, 2]. Medicinal plants have played an important part in global health. Medicinal plant formulations are of immense value in the Indian systems of medicine. The method of prescribing a series of standards or inherent features, constant parameters, definite qualitative and quantitative values that hold an assurance of consistency, effectiveness, purity, and reproducibility is known as standardisation of herbal medicine [3]. However, there is a paucity of documents of standardization protocols for herbal formulation to aid herbal formulation manufacturers, for preparing formulations containing standardized extracts and to increase the global market value and acceptability of herbal medicines $[4,5]$. Hence, the present document sheet is

prepared for the plant Calycopteris floribunda.

Calycopteris floribunda Lam is an ethno medicinal plant that was commonly used to produce a variety of herbal medicines. It is a large climbing shrub that belongs to the Rangoon creeper Combretaceae family. The plant is said to have extensive therapeutic value, with medicinal properties mostly found in the stem and leaves [6]. The plant is referred as lifesaver for forest dwellers [7]. Standardization studies namely organoleptic evaluation, proximate analysis, phytochemical evaluation, quantitative evaluation and biological activity reported for Calycopteris floribunda are reviewed and documented in this paper. All reports of earlier work, including figures are duly cited with reference number in square bracket.
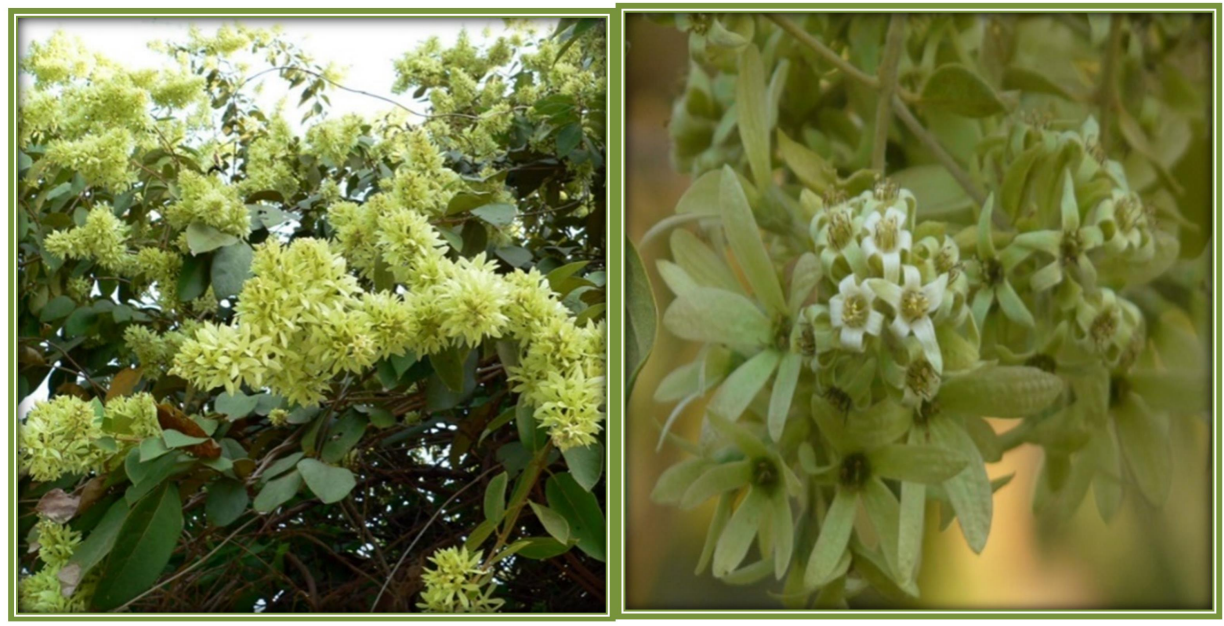

Figure 1: Calycopteris floribunda plant

Rationale

Prior to any significant experimental examination of medicinal plants, a rational approach would be to collect ethnopharmacological data that could be systematically processed to 
provide a preliminary description. guidelines.

However, there is a shortage of standardised procedures for herbal formulation and the chemicals responsible for their therapeutic effects are yet unknown for the majority of them. Hence, we documented the medicinal plant Calycopteris floribunda.

\section{Fact Sheet}

Fact Sheet is a concise account of a plant, its applications, and cultural
Table 1 represents the detailed plant Profile of Calycopteris floribunda.

\section{STANDARDIZATION STRATEGIES}

The chemical, physical, microbiological, therapeutic, and toxicological tests carried out on plant and plant extracts, can be valuable tool in standardization studies [28]. Chart 1 represents the standardization protocols for herbal formulations of plants.

Table 1: Fact Sheet of Calycopteris floribunda [7-27]

\begin{tabular}{|c|c|}
\hline Scientific Name & Calyopteris floribunda (Roxb.) Lam. \\
\hline Taxonomy Id & 134915 \\
\hline Subkingdom & Tracheophyta \\
\hline Class & Magnoliopsida \\
\hline Order & Myrtales \\
\hline Family & Combretaceae \\
\hline Genus & \begin{tabular}{|c|} 
Calycopteris \\
\end{tabular} \\
\hline Synonyms & $\begin{array}{c}\text { Calycopteris nutans, Combretum sericeum, (Roxb.), Calycopteris coccineum } \\
\text { Lam., Calycopteris nutans, Combretum extensumRoxb. and Getonia } \\
\text { floribunda Roxb }\end{array}$ \\
\hline Vernacular names & $\begin{array}{c}\text { Tamil: Pullanji Valli, Minnarkoti, Eruzham } \\
\text { English: Paperflower climber } \\
\text { Hindi :Kokkare } \\
\text { Marathi: Ukshi } \\
\text { Telugu: Murugadutige, bandimurududu } \\
\text { Kannada: Enjarigekubsa } \\
\text { Sanskrit: Susavi, Toyavalli } \\
\text { Malayalam: Pullani, Varavalli }\end{array}$ \\
\hline Common names & Ukshi ,Minnarkodi, Guichalata \\
\hline Special name & $\begin{array}{c}\text { Life Saver - Forest Dwellers } \\
\end{array}$ \\
\hline Morphological Characteristics & $\begin{array}{l}\text { Straggling shrubs, young pubescent. Leaves opposites, flowers I dense } \\
\text { panicles at the ends of branches. Calyx lobes } 5 \text {, white, showy, persistent, } \\
\text { calyx tube elongate, 5-angled produced above the ovary. Petals 0. Stamens } \\
10 \text { in } 2 \text { series. Ovary inferior 1-celled, ovules } 3 \text {. Fruits are brownish or } \\
\text { yellow-tomentose with 5-angled, crowned by accrescent calyx, brownish or } \\
\text { yellow-tomentose and solitary seeds. (www.greenpatio.com) }\end{array}$ \\
\hline Flowering \& Fruiting & January - April \\
\hline Distribution & $\begin{array}{l}\text { Indomalaysia } \\
\end{array}$ \\
\hline Adaptation & $\begin{array}{l}\text { This plant is found extensively within the low-lying tropical evergreen } \\
\text { forests of the Western Ghats, and infrequently in the Eastern Ghats of } \\
\text { coastal Andhra. It is also found in "kavus" or the sacred Groes of Kerala. }\end{array}$ \\
\hline $\begin{array}{l}\text { Number of isolated } \\
\text { chemical constituents }\end{array}$ & Twenty four $[10-22]$ \\
\hline Major Components & $\begin{array}{ll}\text { Flavonoids and Phenols } \\
\end{array}$ \\
\hline Biologically active components & $\begin{array}{c}\text { Calycopterin [11], Pachypodol }[17,18], 3 \text { '-amino-5-hydroxy-3,6,7,8,4'-penta } \\
\text { methoxy flavone [21], Calycopterones, isocalycopterone, 4-methyl } \\
\text { calycopterone [22] }\end{array}$ \\
\hline Biomarker & $\begin{array}{c}\text { A potential anticancer drug lead compound- Pachypodol [18] } \\
\text { Plant Anti-tumor Agents - Calycopterone, iso calycopterone, 4-methyl } \\
\text { calycopterone [22] }\end{array}$ \\
\hline $\begin{array}{l}\text { Quantification of Biomarker } \\
\text { and Protocol adopted }\end{array}$ & $\begin{array}{c}1.983 \mathrm{mg} / \mathrm{g} \text { Pachypodol [18] } \\
\text { Method : High Performance Liquid Chromatography }\end{array}$ \\
\hline
\end{tabular}




\begin{tabular}{|c|c|}
\hline & $\begin{array}{c}\text { Column : Lichrospher C18 } \\
\text { Solvent System : Acetonitrile and ultrapure water } \\
\text { Detector : UV detector } \\
\text { Wavelength } \quad: 365 \mathrm{~nm} \\
\text { Injected Vol. } \quad: 1.0 \mathrm{~mL} \mathrm{~min} \\
\text { Temperature } \quad: 35^{\circ} \mathrm{C} \\
\end{array}$ \\
\hline Therapeutic and other attributes & $\begin{array}{l}\text { Used for worm infestations, anaemia, obstinate skin diseases and fever } \\
\text { (therapeutic uses of leaf, stem and root) }\end{array}$ \\
\hline Folk use & $\begin{array}{l}\text { Leaves are bitter useful in intestinal worms, laxative, colic, astringent, } \\
\text { antiseptic, wounds leprosy malaria fever, dysentery, ulcers, vomiting. The } \\
\text { fruit is useful in treating jaundice, ulcers and skin diseases. }\end{array}$ \\
\hline Medicinal Part & Leaves \\
\hline Pharmacological potential & $\begin{array}{c}\text { Antioxidant, anti-inflammatory, antifungal, antimicrobial, antibacterial, } \\
\text { hepatoprotective, } \beta \text { - glucuronidase inhibition activity }\end{array}$ \\
\hline Dosage and safety aspects & $\begin{array}{c}\text { Morbidity and mortality were observed in rats and rabbits. Calycopterin } \\
\text { and its 4'-methyl ether derivative exhibited marked toxicity to fish. }\end{array}$ \\
\hline Databases & $\begin{array}{c}\bullet \quad \text { NAPRALERTTM database } \\
\begin{array}{c}\text { National Resource Conservation Service-Plants Database of USDA (United } \\
\text { States Department of Agriculture) }\end{array} \\
\end{array}$ \\
\hline History & $\begin{array}{c}\text { Protologue: Enchycl., suppl. 2:41 (1811) } \\
\text { Family: Combretaceae } \\
\text { Chromosome number; } 2 \mathrm{n}=48 \\
\text { (Plant Resources of South-East Asia ) }\end{array}$ \\
\hline
\end{tabular}

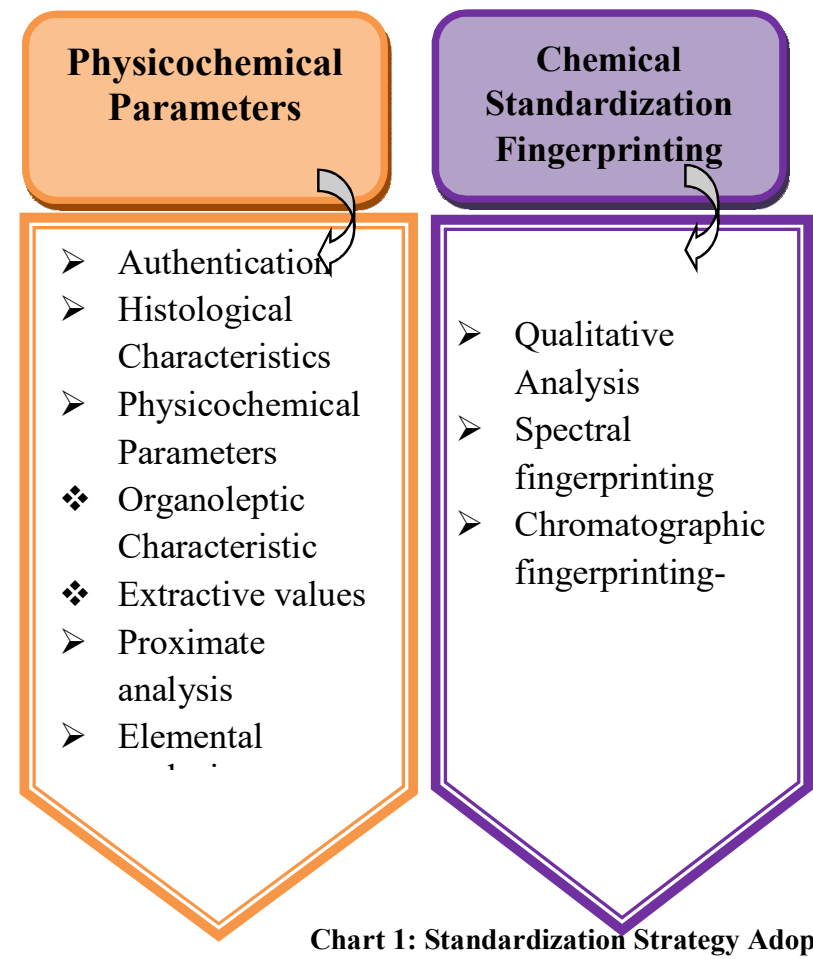

Histological Characteristics

The structure and growth of the phloem in the stems of Calycopteris floribunda plant were studied [29]. Cells in the centre of the cambial zone

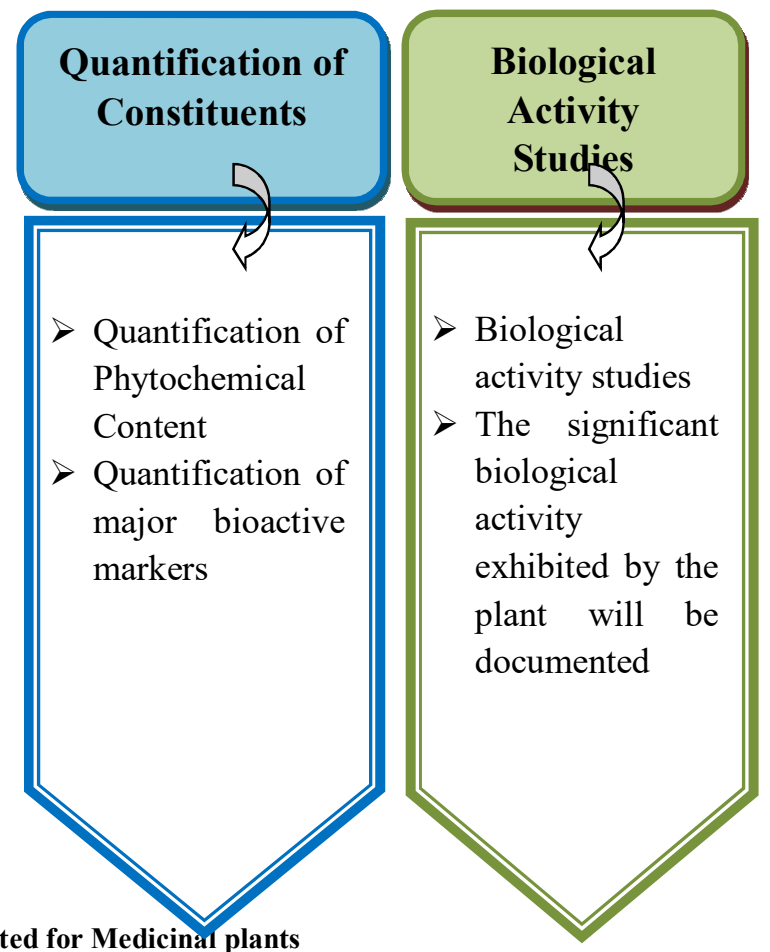

differentiated into their descendants in tiny segments of the cambium, resulting in the cambial zone being divided into outer and inner segments. The outside segment connected with the existing cambial ring to 
re-establish the cambial cylinder, whereas the inner segment was surrounded by differentiating xylem. This process is repeated multiple times, leading in the development of a number of phloem islands embedded in secondary xylem. Figure 2 shows the transverse, tangential and radial longitudinal view of secondary xylem.

\section{PHYSICOCHEMICAL PARAMETERS}

Organoleptic Characteristics and Extraction efficacy

Soaking and refluxing methods were employed to find the extraction efficacy of solvent for extracting the plant material. The colour and yield of the petroleum ether, methanol, chloroform, hexane, ethyl acetate, hydroethanol extracts of Calycopteris floribunda are tabulated (Table 2).
Proximate Analysis

Proximate parameters namely moisture content, ash content and watersoluble content were determined for airdried powdered leaf material. Calycopteris floribunda contains $22.72 \%$ ash content, $3.97 \%$ moisture content and $24.55 \%$ watersoluble extract. The percentage of ash content and water soluble content is an indication of the content of polar molecules and glycosides.

\section{Elemental Analysis}

Calcium, magnesium, sodium, potassium, zinc, copper, chromium, lithium and nickel content have been determined by EDXRF technique [26], ICP - OES method [34], and EDX metal content analysis method. Table 3 shows the metal content values for flowers and leaves of Calycopteris floribunda.

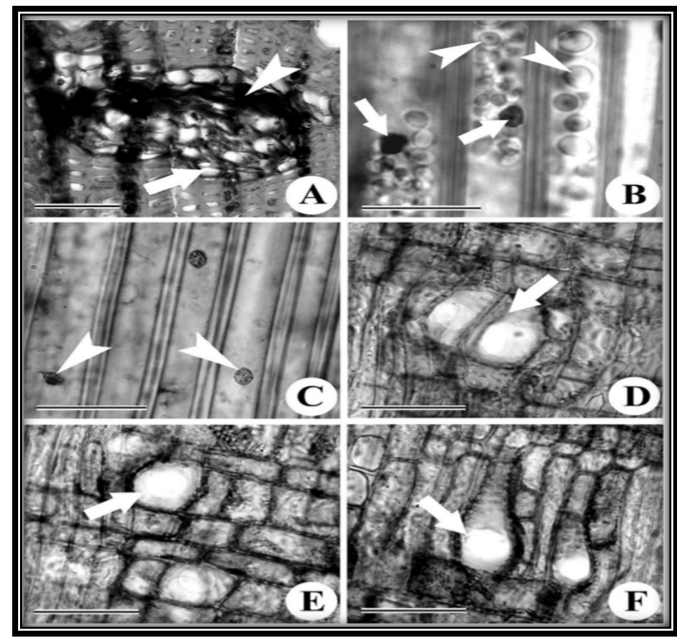

Figure 2: Transverse (A), tangential (B and C) and radial (D-F) longitudinal view of secondary xylem of Calycopteris floribunda [29] 


\begin{tabular}{|c|c|c|c|c|c|}
\hline \multicolumn{6}{|c|}{ Table 2: Organoleptic Properties and Extractive Value } \\
\hline S.No & Part & Method & Extracts & Colour & Yield (\%) \\
\hline 1 & \multirow{4}{*}{ Leaves [27] } & \multirow[t]{4}{*}{ Soxhlet } & Pet Ether & Brown & 2.78 \\
\hline 2 & & & Chloroform & Greenish Black & 5.81 \\
\hline 3 & & & Methanol & Green & 9.81 \\
\hline 4 & & & Aqueous & Brown & 8.71 \\
\hline 5 & \multirow[t]{3}{*}{ Flowers [30] } & \multirow[t]{3}{*}{ Soxhlet } & Pet Ether & Golden Yellow & $\mathbf{0 . 7 0}$ \\
\hline 6 & & & Chloroform & Dark Green & $\mathbf{1 . 3 0}$ \\
\hline 7 & & & Methanol & Brownish Orange & 6.70 \\
\hline 8 & \multirow{5}{*}{$\begin{array}{c}\text { Leaves } \\
\text { (Present Work) }\end{array}$} & \multirow[t]{3}{*}{ Soxhlet } & Hexane & Greenish Brown & 0.94 \\
\hline 9 & & & Ethyl Acetate & Dark Green & 1.51 \\
\hline 10 & & & Hydroethanol & Dark Green & 8.55 \\
\hline 11 & & \multirow[t]{2}{*}{ Reflux } & Hexane & Greenish Brown & 3.46 \\
\hline 12 & & & Hydroethanol & Dark Green & 3.47 \\
\hline
\end{tabular}

Table 3: Elemental Analysis of Calycopteris floribunda

\begin{tabular}{|c|c|c|c|c|}
\hline S.No & Elements & $\begin{array}{c}\text { Root - Concentration } \\
\left(\mathrm{mg} \mathrm{kg}^{-1}\right)[26]\end{array}$ & $\begin{array}{l}\text { Flowers } \\
(\mathrm{ppm})[34]\end{array}$ & $\begin{array}{c}\text { Leaves (\%) } \\
\text { (Present Work) }\end{array}$ \\
\hline 1. & Calcium & - & 6977.93 & 6.39 \\
\hline 2. & Magnesium & - & 2638.79 & 0.81 \\
\hline 3. & Sodium & - & 103.30 & 0.88 \\
\hline 4. & Potassium & - & 8829.19 & 14.05 \\
\hline 5. & Iron & - & 378.86 & - \\
\hline 6. & Manganese & 3924.1 & 340.52 & 0.81 \\
\hline 7. & Zinc & 148.7 & 13.57 & - \\
\hline 8. & Copper & & 12.59 & - \\
\hline 9. & Lithium & - & 5.39 & - \\
\hline 10. & Chlorine & - & - & 6.39 \\
\hline 11. & Aluminium & - & - & 0.75 \\
\hline 12. & Silicon & - & - & 0.29 \\
\hline 13. & Carbon & - & - & 30.28 \\
\hline 14. & Oxygen & - & - & 40.36 \\
\hline 15. & Nitrogen & - & - & 6.19 \\
\hline 16. & Nickel & 50.5 & - & - \\
\hline
\end{tabular}

\section{CHEMICAL STANDARDIZATION OF}

\section{EXTRACTS}

\section{Qualitative Analysis}

The preliminary phytochemical analysis was done by standard procedure and reported $[7,9,14,27,31-34]$. Table 4 represents the preliminary phytochemical screening for the various extracts of Calycopteris floribunda.

\section{SPECTRAL FINGERPRINTING OF EXTRACTS}

\section{UV-Visible Spectral Fingerprinting}

UV-Visible spectrophotometric analysis was done in UV-Systronics AR 2701 double beam spectrophotometer.
Figures 3 and 4 represent the UV spectral fingerprinting of the non-polar CAFL $(\mathrm{H})$ and polar CAFL (HE) extracts respectively.

Figure 5, represents the overlay spectra showing a shift in wavelength of the longer wavelength band. A bathochromic shift was observed at $375 \mathrm{~nm}$ for the hydroethanol extract with the shift reagent sodium ethoxide. This shift indicates the presence of flavonoidal hydroxyl groups in Calycopteris floribunda leaf extract.

Table 5 represents the UV absorption $\lambda \max$ for various chemical 
compounds isolated from Calycopteris

floribunda.

\section{FT-IR Spectral Fingerprinting}

FT-IR spectrometer Shimatzu-

Miracle 10 make was used for recording the IR spectrum for Calycopteris floribunda extracts. Figures 6 and 7 represent the FT-IR fingerprints of the nonpolar and polar extracts respectively. The IR spectrum of CAFL $(\mathrm{H})$ indicates the presence of non-polar constituents mostly while the CAFL (HE) indicates the presence of polar groups.

Table 6 provides the IR absorptions of various chemical compounds isolated from Calycopteris floribunda.
${ }^{1} \mathrm{H}$ NMR spectral fingerprinting of the extracts CAFL (H) and CAFL (HE) were recorded in Bruker $300 \mathrm{MHz}$ Proton Nuclear Magnetic Resonance under room temperature. The extracts were dissolved d6-DMSO.The proton NMR spectral fingerprints for CAFL $(\mathrm{H})$ and CAFL (HE) are represented by Figures 8 and 9.

\section{CHROMATOGRAPHIC}

\section{FINGERPRINTING OF EXTRACTS}

\section{Thin Layer Chromatography}

TLC analysis was obtained for nonpolar and polar extracts of Calycopteris floribunda. The optimized TLC developing solvent system for the extracts is given in following Table 7.

\section{NMR Spectral Fingerprinting}

Table 4: Qualitative Analysis of Calycopteris floribunda $[7,9,14,27,31-34$

\begin{tabular}{|c|c|c|c|c|c|c|}
\hline \multirow[b]{2}{*}{ Phytochemicals } & \multicolumn{6}{|c|}{ Extracts } \\
\hline & Pet Ether & Chloroform & Ethyl Acetate & Methanol & Ethanol & Aqueous \\
\hline Carbohydrates & - & - & - & + & - & + \\
\hline Glycosides & - & - & + & + & - & + \\
\hline Proteins & - & - & - & + & - & + \\
\hline Alkaloids & - & + & + & - & + & - \\
\hline Steroids & + & + & + & + & - & + \\
\hline Terpenoids & - & + & + & + & - & + \\
\hline Flavonoids & - & + & + & + & + & + \\
\hline Saponins & - & - & + & + & - & + \\
\hline Phenolics & - & - & + & + & - & + \\
\hline
\end{tabular}

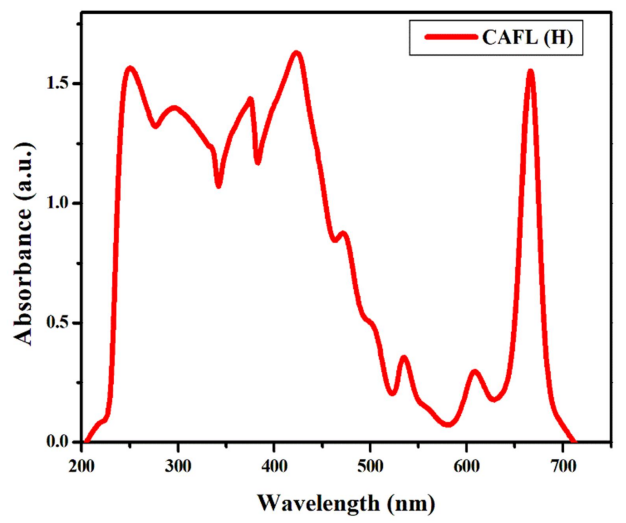

Figure 3: UV fingerprints of CAFL (H) 


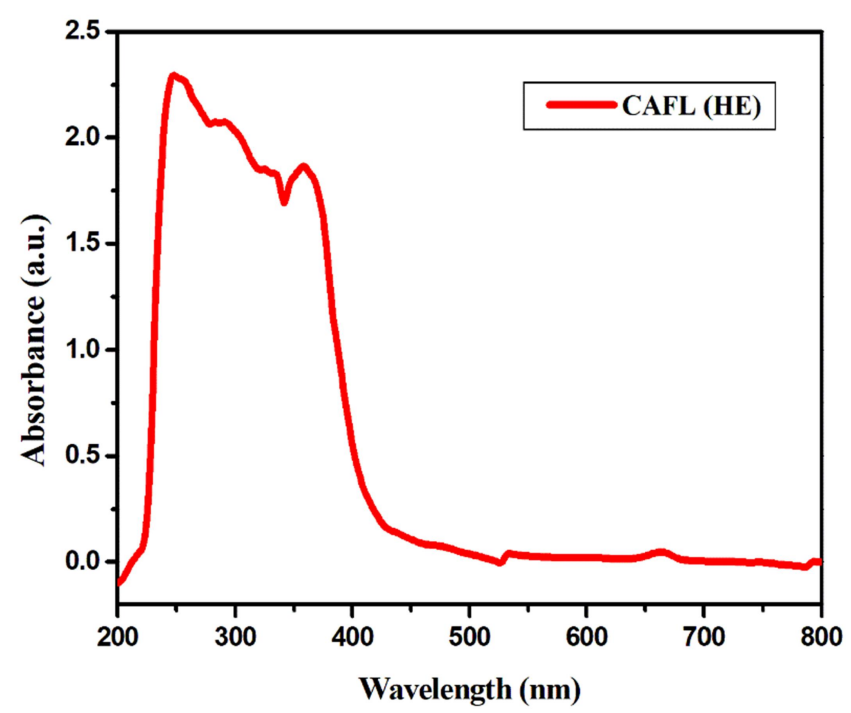

Figure 4: UV fingerprints of CAFL (HE)

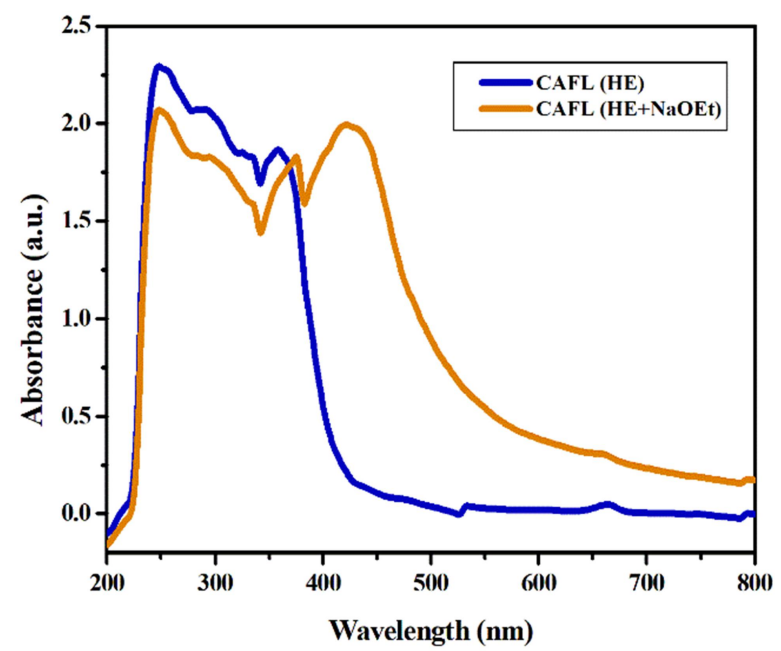

Figure 5: Overlay of UV Spectrum of CAFL (HE) with UV Spectrum of CAFL (HE+NaOEt)

Table 5: UV absorption $\lambda$ max for Calycopteris floribunda Compounds

\begin{tabular}{|c|c|c|c|}
\hline S.No & Extracts /Compounds & Solvents and Shift reagents & $\begin{array}{l}\text { Absorption } \\
\lambda \max (\mathrm{nm})\end{array}$ \\
\hline \multirow[t]{6}{*}{1} & \multirow[t]{6}{*}{ Pachypodol [17] } & $\mathrm{MeOH}$ & 357,270 \\
\hline & & $\mathrm{MeOH}+\mathrm{NaOMe}$ & $404,357,266$ \\
\hline & & $\mathrm{MeOH}+\mathrm{AlCl}_{3}$ & $398,362,268$ \\
\hline & & $\mathrm{MeOH}+\mathrm{AlCl}_{3} / \mathrm{HCl}$ & $396,360,266$ \\
\hline & & $\mathrm{MeOH}+\mathrm{NaOAc}$ & 360,255 \\
\hline & & $\mathrm{MeOH}+\mathrm{NaOAc} / \mathrm{H}_{3} \mathrm{BO}_{3}$ & 357,254 \\
\hline 2 & Calyflorenone A [19] & EtOH & 292,258 \\
\hline \multirow[t]{2}{*}{3} & \multirow{2}{*}{ Calyflorenone B [19] } & EtOH & $296,259,212$ \\
\hline & & EtOH + NaoMe & $296,258,211$ \\
\hline 4 & Neocalycopterone [19] & EtOH & 288 \\
\hline 5 & Neocalycopterone-4-methyl ether [19] & EtOH & 288,209 \\
\hline 6 & 6"-Demethoxy neocalycopterone [20] & EtOH & $295,257,212$ \\
\hline 7 & Calyflorenone $\mathrm{C}[20]$ & EtOH & $294,258,213$ \\
\hline 8 & 6"-Epi-calyflorenone B [20] & EtOH & $294,257,212$ \\
\hline 9 & 6"-Epi-calyflorenone C [20] & EtOH & $295,257,215$ \\
\hline 10 & Calyflorenone D [20] & EtOH & $295,257,211$ \\
\hline 11 & Calycopterone [22] & МeOH & 289 \\
\hline 12 & Isocalycopterone [22] & МeOH & 277 \\
\hline
\end{tabular}




\begin{tabular}{|c|c|c|c|}
\hline 13 & 4-Demethylcalycopterone $[22]$ & МeOH & 288 \\
\hline 14 & $\begin{array}{c}\text { 4',5-Dihydroxy-3,3',6,7-tetramethoxyflavone } \\
{[22]}\end{array}$ & МeOH & $350,270,256$ \\
\hline 15 & $\begin{array}{c}\text { CAFL (H) Extract } \\
\text { (Present Work) }\end{array}$ & Hexane & $\begin{array}{c}666,609,535,423, \\
375,297,251\end{array}$ \\
\hline \multirow[t]{2}{*}{16} & \multirow{2}{*}{$\begin{array}{l}\text { CAFL (HE) Extract } \\
\text { (Present Work) }\end{array}$} & EtOH & $664,359,248$ \\
\hline & & EtOH +NaoEt & $423,375,249$ \\
\hline
\end{tabular}

*EtoH - Ethanol; MeOH - Methanol; NaOMe - Sodium Methoxide; NaOAc- Sodium Acetate; NaOEt - Sodium Ethoxide

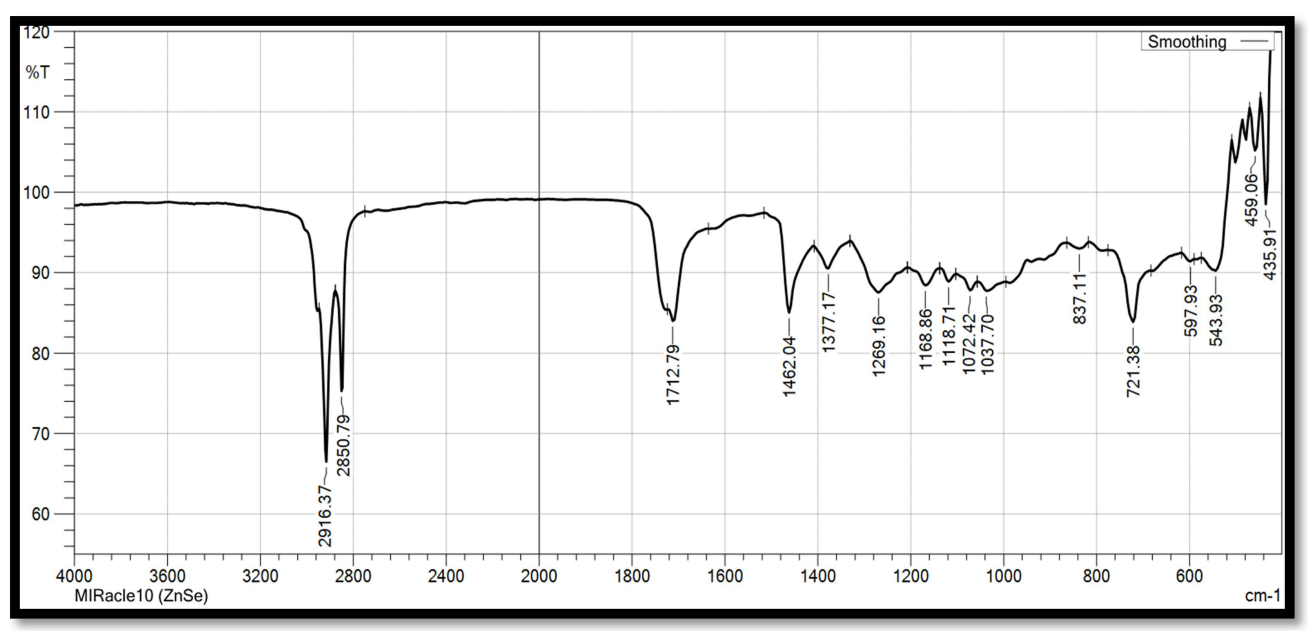

Figure 6: FTIR fingerprint of CAFL (H)

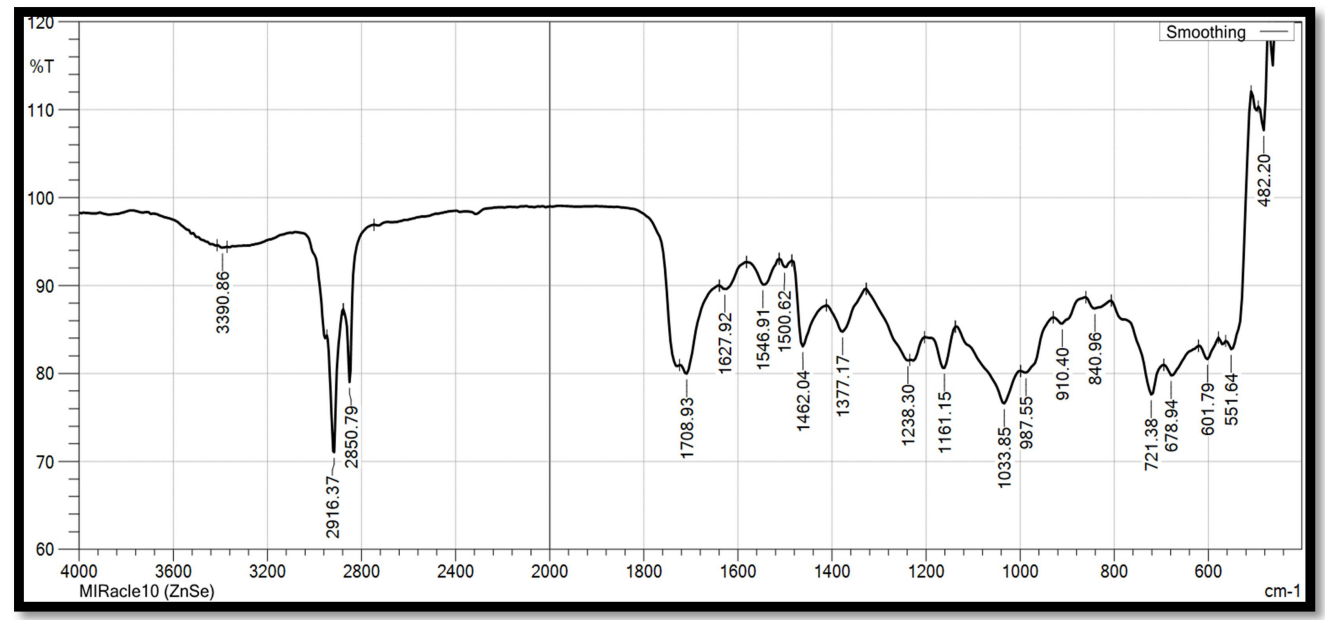

Figure 7: FTIR fingerprint of CAFL (HE)

Table 6: IR Absorptions of Compounds isolated from Calycopteris floribunda

\begin{tabular}{|c|c|c|}
\hline S.No & Extracts /Compounds & Absorption Frequency $\left(\mathrm{cm}^{-1}\right)$ \\
\hline 1 & Calyflorenone A [19] & $\begin{array}{c}\text { 3440, 2930, 2840, } 1665,1630-1600,1450,1250,1195,1170, \\
1135,1085,1030,700\end{array}$ \\
\hline 2 & Calyflorenone B [19] & $\begin{array}{c}3430,3075,3040,2940,2840,1665,1635,1600,1450,1195, \\
1170,1090,1020,765,700\end{array}$ \\
\hline 3 & Neocalycopterone [19] & $\begin{array}{c}3470,3100,3070,3040,2940,2840,1670,1630,1600,1450, \\
1330,1025,925,760,700\end{array}$ \\
\hline 4 & Neocalycopterone-4-methyl ether [19] & $\begin{array}{c}3450,3060,3040,2940,2830,1670,1630,1595,1450,1325 \\
1095,1025,920,700\end{array}$ \\
\hline 5 & 6'-Demethoxy neocalycopterone [20] & $\begin{array}{c}\text { 3394, 2930, 1669, 1630, 1602, 1456, 1234, 1170, 1068, 1045, } \\
913,765,700 .\end{array}$ \\
\hline 6 & Calyflorenone C [20] & $\begin{array}{c}3424,2933,2835,1662,1635,1602,1457,1260,1194,1163, \\
1126,1090,1020,801,699\end{array}$ \\
\hline 7 & 6'-Epi-calyflorenone B [20] & $\begin{array}{c}2928,2829,1675,1619,1609,1457,1330,1289,1248,1195, \\
1161,1092,1027,761,700\end{array}$ \\
\hline 8 & 6"-Epi-calyflorenone C [20] & $2930,2852,1675,1616,1457,1252,1193,1161,1094,1041$, \\
\hline
\end{tabular}




\begin{tabular}{|c|c|c|}
\hline & & $1061,1020,870,760,700$ \\
\hline 9 & Calyflorenone D [20] & $\begin{array}{c}3372,2925,2851,1653,1457,1327,1288,1194,1162,1089, \\
1023,869,760,700\end{array}$ \\
\hline 10 & Calycopterone [22] & $3485,3400,2915,1660,1620,1595,1448,1317,1157$ \\
\hline 11 & Isocalycopterone [22] & $\begin{array}{c}3480,2910,1661,1631,1591,1444,1420,1317,1096,1030, \\
933\end{array}$ \\
\hline 12 & 4-Demethylcalycopterone [22] & $\begin{array}{c}3480,2815,1660,1628,1601,1492,1446,1315,1156,1034, \\
918\end{array}$ \\
\hline 13 & CAFL (H) Extract (Present Work) & $2916,2850,1713,1462,1377,1169,721$ \\
\hline 14 & CAFL (HE) Extract (Present Work) & $2916,2851,1709,1547,1462,1377,1238,1161,1034,721$ \\
\hline
\end{tabular}

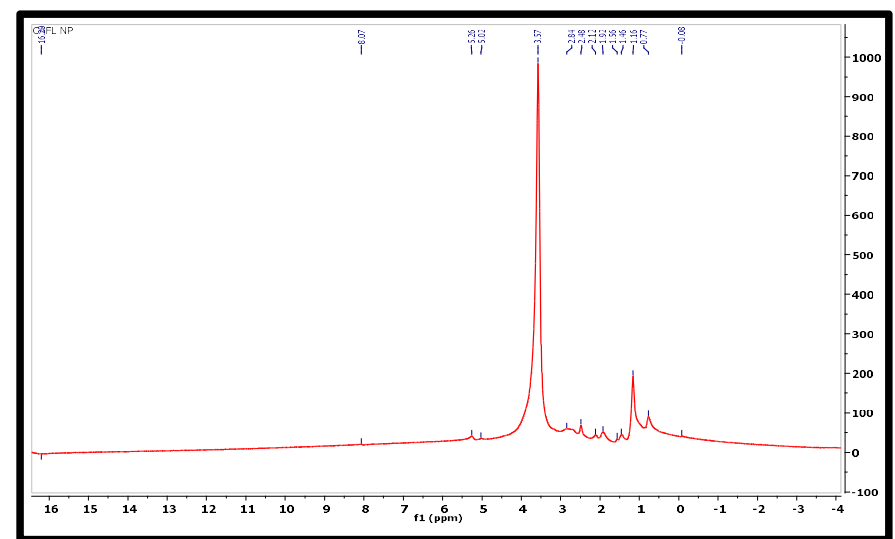

Figure 8: ${ }^{1} \mathrm{H}$ NMR Spectral fingerprint of CAFL (H)

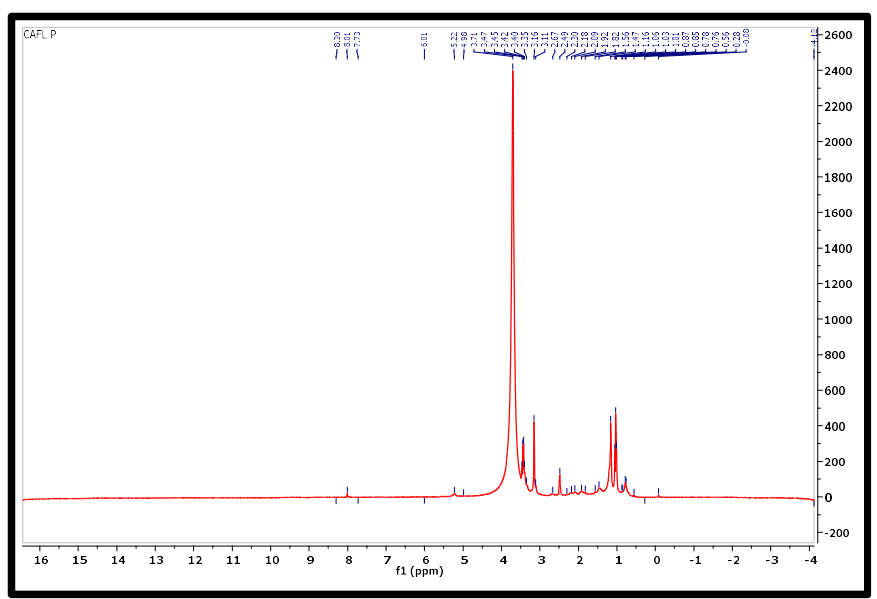

Figure 9: ${ }^{1} \mathrm{H}$ NMR Spectral fingerprint of CAFL (HE)

Table 7: Optimized TLC Solvent System

\begin{tabular}{|c|c|}
\hline Extracts & Solvent System \\
\hline CAFL (H) & Hexane : Ethyl acetate $7: 3$ \\
\hline CAFL (HE) & Hexane : Ethyl acetate 6:4 \\
\hline
\end{tabular}

\section{GC-MS Fingerprinting}

Clarus 680 GC, Clarus 600(EI)

Mass spectrometer and Agilent (GC) JEOL

GC MATE II (MS) was used for recording the non-polar extract and polar Calycopteris floribunda extracts respectively. 
GC-MS Protocol for CAFL (H) (SIF-VIT, Vellore)

CAFL (H)

- Oven temperature : Initial temperature $60^{\circ} \mathrm{C}$ for 2 minutes, ramp $10^{\circ} \mathrm{C} / \mathrm{min} 300^{\circ} \mathrm{C}$ hold 6 minutes.

- Total run time : 32 minutes

- Auto injector run : $260^{\circ} \mathrm{C}$

- Sample volume : $1 \mu 1$

- Split ratio : 10:1

- Flow rate : $1 \mathrm{~mL} / \mathrm{min}$

- Carrier gas : Helium

- Solvent delay : 2 minutes

- Ion source temperature : $230^{\circ} \mathrm{C}$

- Scan : 50 to $600 \mathrm{Da}$

GC-MS Protocol for CAFL (HE) (SAIF-IIT, Chennai)

\section{CAFL (HE)}

- Column - HP 5 MS

- Oven temperature : Initial temperature $50^{\circ} \mathrm{C}$ for 2 minutes, ramp $10^{\circ} \mathrm{C} / \mathrm{min} 250^{\circ} \mathrm{C}$ hold 6 minutes.

- Total run time : 40 minutes

- Auto injector run : $260^{\circ} \mathrm{C}$

- Sample volume : $1 \mu 1$

- Flow rate : $1 \mathrm{~mL} / \mathrm{min}$

- Carrier gas : Helium

- Ion source temperature : $250^{\circ} \mathrm{C}$

- Scan : 50 to $600 \mathrm{amu}$

Figures 10 and 11 represents the GC-MS fingerprint for CAFL $(\mathrm{H})$ and CAFL (HE) respectively. The prominent peaks with an area greater than $10 \%$ in the total ion chromatogram were noted. The probable compounds predicted based on NIST library search are listed in Table 8.

\section{HPLC Fingerprinting}

HPLC analysis was performed to assess the chemical profile of Calycopteris floribunda leaf extracts produced by supercritical fluid extraction (SFE) and
Carbon dioxide-ethanol (CE) technique [18]. In Figure 12 [18] shown below, curve 1 represents the HPLC fingerprints of crude flavonoid fraction of leaves obtained by supercritical fluid extraction and curve 2 represents the HPLC fingerprints of crude flavonoid fraction of leaves obtained by $\mathrm{CE}$ technique. The peak at retention time near 4.5 identified as pachypodol.

\section{Quantitative Analysis}

The flavonoid and phenolic content of dried leaves was determined by standard 
procedure and the reported results were tabulated (Table 9).

\section{Chemical Constituents isolated from}

\section{Calycopteris floribunda}

The first isolation of chemical constituents from Calycopteris floribunda was reported in 1934. Table 10 provides the details of the chemical constituents isolated from the various parts of Calycopteris floribunda.

The structures of the chemical constituents isolated from this plant are represented in Chart 2.

Quantification of Biomarker Pachypodol [18]

So far, around 24 chemical constituents of Calycopteris floribunda have been isolated. Among these, the compounds calycopterin, calycopterones, isocalycopterone, 4-methyl calycopterone, 3'-amino-5-hydroxy-3,6,7,8,4'-

pentamethoxy flavone and pachypodol have been reported as flavonoid markers. Among these markers, pachypodol was quantified from the leaf extracts of Calycopteris floribunda by an optimized HPLC method.

Figure 13 shows the HPLC results obtained for extracts of Calycopteris floribunda and the standard Pachypodol. Curve 1 represents the HPLC chromatogram of the compound Pachypodol.

The HPLC quantification revealed the presence of $1.983 \mathrm{mg} / \mathrm{g}$ pachypodol in the leaf extract of Calycopteris floribunda.

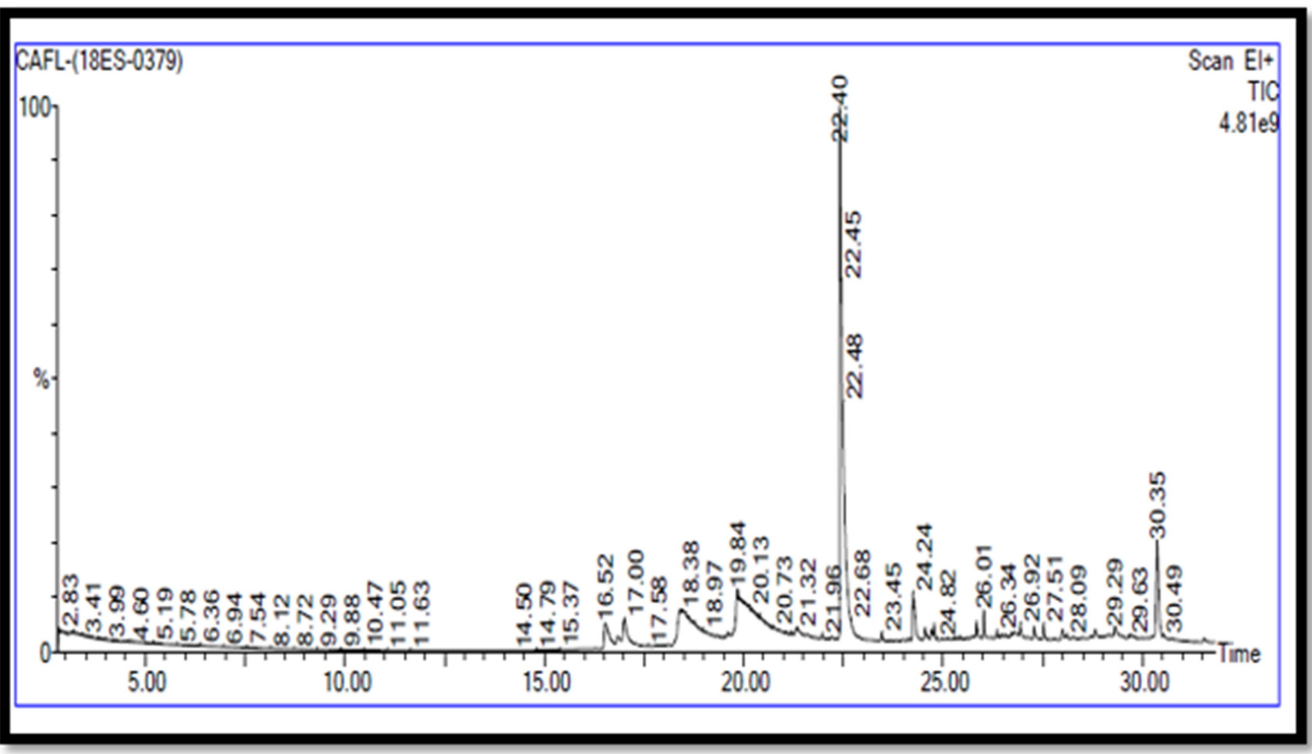

Figure 10: Gas Chromatogram of CAFL (H) 


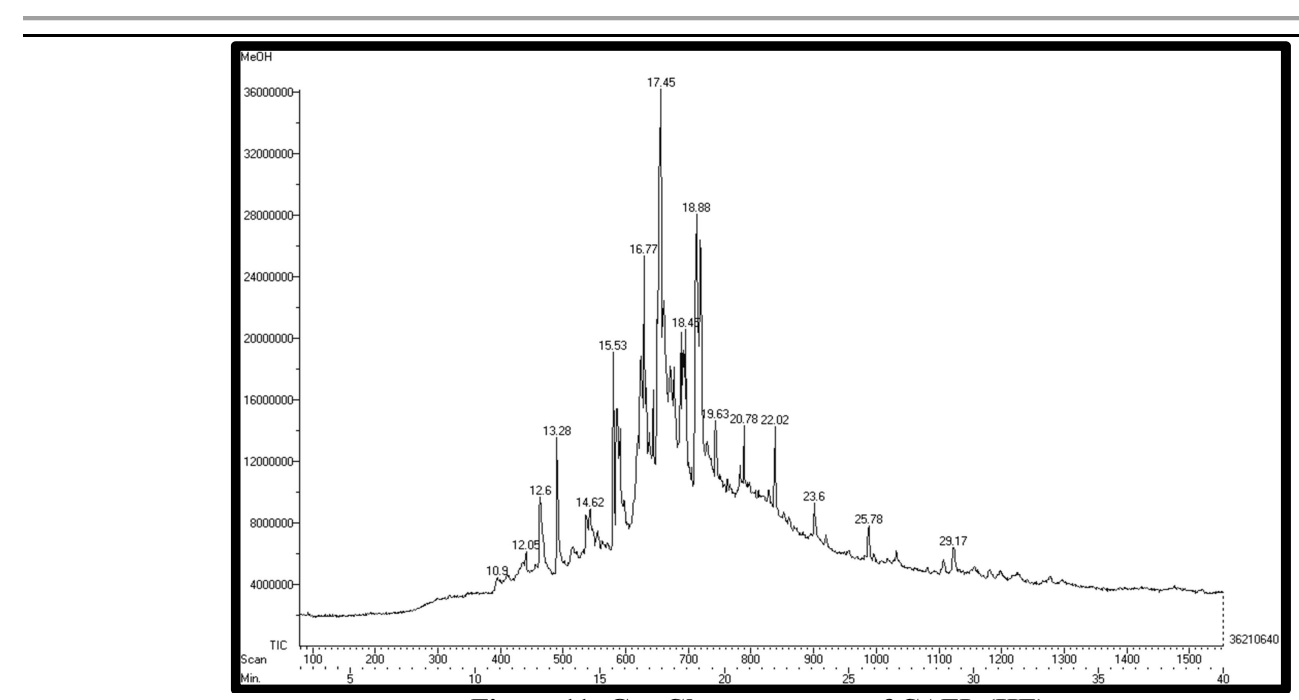

Figure 11: Gas Chromatogram of CAFL (HE)

Table 8: Compounds Predicted from NIST Database for CAFL extracts

\begin{tabular}{|c|c|c|c|}
\hline \multicolumn{2}{|c|}{ CAFL (H) } & \multicolumn{2}{|r|}{ CAFL (HE) } \\
\hline $\begin{array}{l}\text { Retention Time } \\
\text { (min.) }\end{array}$ & Probable Compounds & $\begin{array}{l}\text { Retention Time } \\
\text { (min.) }\end{array}$ & Probable Compounds \\
\hline 16.52 & $\begin{array}{c}\text { 3,7,11,15-tetramethyl-2- } \\
\text { hexadecen-1-ol }\end{array}$ & 12.66 & $\begin{array}{c}\text { 4-hydroxy-3-methoxybenzyl } \\
\text { alcohol } \\
\end{array}$ \\
\hline 17.01 & Phytol & 15.53 & a-caryophyllene \\
\hline 18.47 & N-hexadecanoic acid & 17.45 & n-hexadexanoic acid \\
\hline 19.84 & (Z)-14-tricosenyl formate & 18.88 & Oleic acid \\
\hline 20.40 & 1,2-15,16-diepoxyhexadecane & 19.63 & $\begin{array}{c}\text { 9,15-octadecadienoic acid, methyl } \\
\text { ester }\end{array}$ \\
\hline 22.40 & Di-N-octyl phthalate & 20.78 & $\begin{array}{l}\text { Phytol } \\
\end{array}$ \\
\hline $\mathbf{3 0 . 3 5}$ & $\begin{array}{c}\text { 3,7,11,15-tetramethyl-2- } \\
\text { hexadecen-1-ol }\end{array}$ & 23.60 & 1-tetradecene,2-decyl- \\
\hline
\end{tabular}

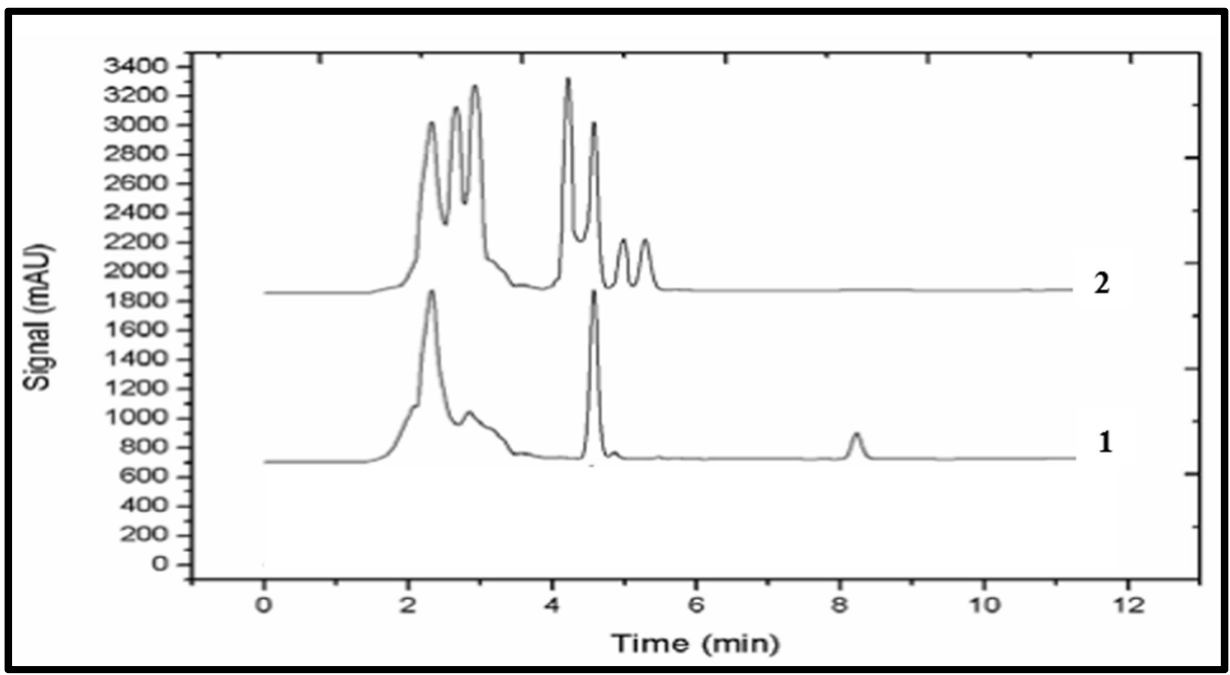

Figure 12: HPLC Fingerprints of crude flavonoid fractions of Calycopteris floribunda [18]

Table 9: Quantitative Analysis of Calycopteris floribunda $[8,30]$

\begin{tabular}{|c|c|c|}
\hline Extracts & Total Flavonoid Content & Total Phenolic Content \\
\hline Petroleum ether & $0.038 \pm 0.076 \mathrm{mg} / \mathrm{g}$ & -- \\
\hline Ethyl acetate & $3.545 \pm 0.023 \mathrm{mg} / \mathrm{g}$ & -- \\
\hline Methanol & $1.489 \pm 0.043 \mathrm{mg} / \mathrm{g}$ & -- \\
\hline Petroleum ether & $25.68 \mu \mathrm{g} \mathrm{CE} / \mathrm{mg}$ & $25.68 \mu \mathrm{g} \mathrm{GAE} / \mathrm{mg}$ \\
\hline Chloroform & $55.85 \mu \mathrm{g} \mathrm{CE} / \mathrm{mg}$ & $55.85 \mathrm{GAE} / \mathrm{mg}$ \\
\hline Methanol & $48.50 \mu \mathrm{g} \mathrm{CE} / \mathrm{mg}$ & $\mathbf{2 8 0 . 3 1} \boldsymbol{\mu g ~ G A E} / \mathrm{mg}$ \\
\hline
\end{tabular}


Table 10: Isolation of Chemical Constituents from Calycopteris floribunda [8]

\begin{tabular}{|c|c|c|c|}
\hline S.No & Plant Part & Solvents & Compound \\
\hline 1 & \multirow[t]{19}{*}{ Leaves } & Dichloro methane methanol & 3, 8-di-O-methyl ellagic acid [10] \\
\hline 2 & & Dichloro methane- methanol & 2,3,7-tri-O-methyl ellagic acid [10] \\
\hline 3 & & Acetone, Benzene, Methanol & Calycopterin [11-15] \\
\hline 4 & & Petroleum ether & n-octacosanol [14] \\
\hline 5 & & Petroleum ether & Sitosterol [14] \\
\hline 6 & & Petroleum ether & 4'-O-methylcalycopterin [14] \\
\hline 7 & & Petroleum ether & Ellagic acid [14] \\
\hline 8 & & Petroleum ether & Proanthocyanidin [14] \\
\hline 9 & & Petroleum ether, Methanol & Quercetin [14-15] \\
\hline 10 & & --- & Calycopterin-4'-methyl ether [16] \\
\hline 11 & & $-\operatorname{los}^{--}$ & 3'-methoxy Calycopterin [16] \\
\hline 12 & & Dichloro methane-methanol, Ethanol & Pachypodol [17-18] \\
\hline 13 & & $\begin{array}{l}\text { Ethanol } \\
\end{array}$ & Neo calycopterone [19] \\
\hline 14 & & Ethanol & 4-Acetyl neocalycopterone [19] \\
\hline 15 & & Ethanol & Neocalycopterone 4- methyl ether [19] \\
\hline 16 & & Ethanol, Ethyl acetate & Calyflorenone A-C [19-20] \\
\hline 17 & & Ethyl acetate & 6"-demethoxy neocalycopterone [20] \\
\hline 18 & & Ethyl acetate & 6"-epi-calyflorenone $[20]$ \\
\hline 19 & & Dichloro methane & $5,3^{\prime}$-dihydroxy-3,6,7,8,4'-pentamethoxy-flavone [21] \\
\hline 20 & \multirow[t]{5}{*}{ Flowers } & Methanol & Gossypol [15] \\
\hline 21 & & 50\% Methanol/ Chloroform & Calycopterone [22] \\
\hline 22 & & 50\% Methanol/ Chloroform & Isocalycopterone [22] \\
\hline 23 & & 50\% Methanol/ Chloroform & 4-demethyl calycopterone [22] \\
\hline 24 & & 50\% Methanol/ Chloroform & 4', 5-dihydroxy-3,3',6, 7-tetra methoxy flavone [22] \\
\hline
\end{tabular}<smiles>COc1c(O)cc2c(=O)oc3c(OC)c(O)cc4c(=O)oc1c2c34</smiles>

3,8-Di-O-methyl ellagic acid<smiles>COc1cc2oc(=O)c3cc(O)c(O)c4c(=O)oc(c1C)c2c34</smiles>

2,3,7-Tri-O-methyl ellagic acid<smiles>COc1c(OC)c(O)c2c(=O)c(OC)c(-c3cccc(O)c3)oc2c1OC</smiles>

Calycopterin

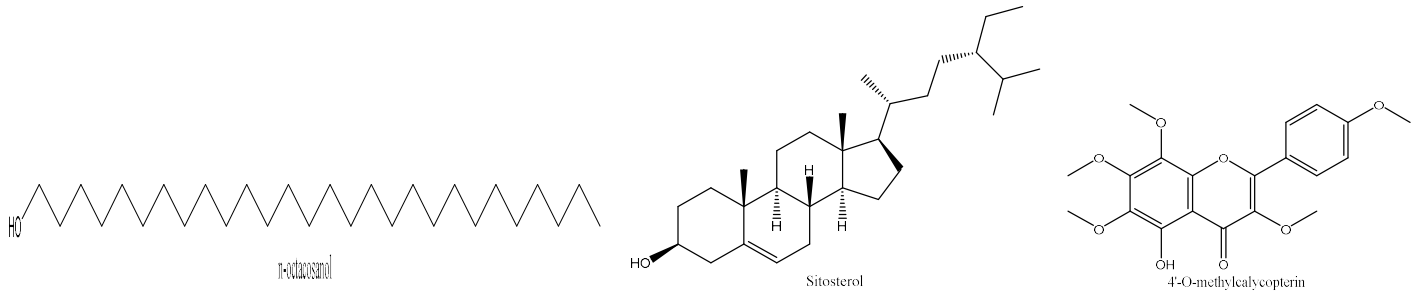<smiles>O=c1oc2c(O)c(O)cc3c(=O)oc4c(O)c(O)cc1c4c23</smiles><smiles>COc1c(O)cc(C2C[C@@H](C)c3c(O)cc(O)c([C@@H]4c5c(O)cc(O)cc5O[C@H](c5ccc(O)cc5)[C@H]4C)c3O2)cc1O</smiles><smiles>O=c1c(O)c(-c2ccc(O)c(O)c2)oc2cc(O)cc(O)c12</smiles> 

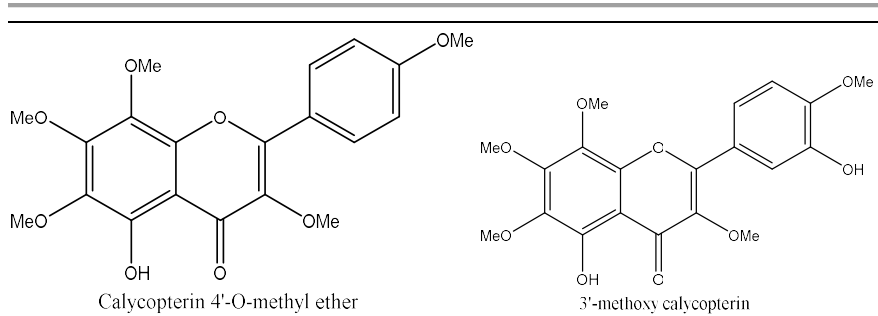<smiles>COc1cc(O)c2c(=O)c(OC)c(-c3ccc(O)c(OC)c3)oc2c1</smiles><smiles>CCc1c(OC)c2c(c3c1[C@]1(OC)C(OC)=C(OC)C(=O)C4=CCC(c5ccccc5)O[C@]41O3)[C@@H](O)CC(c1ccccc1)O2</smiles>
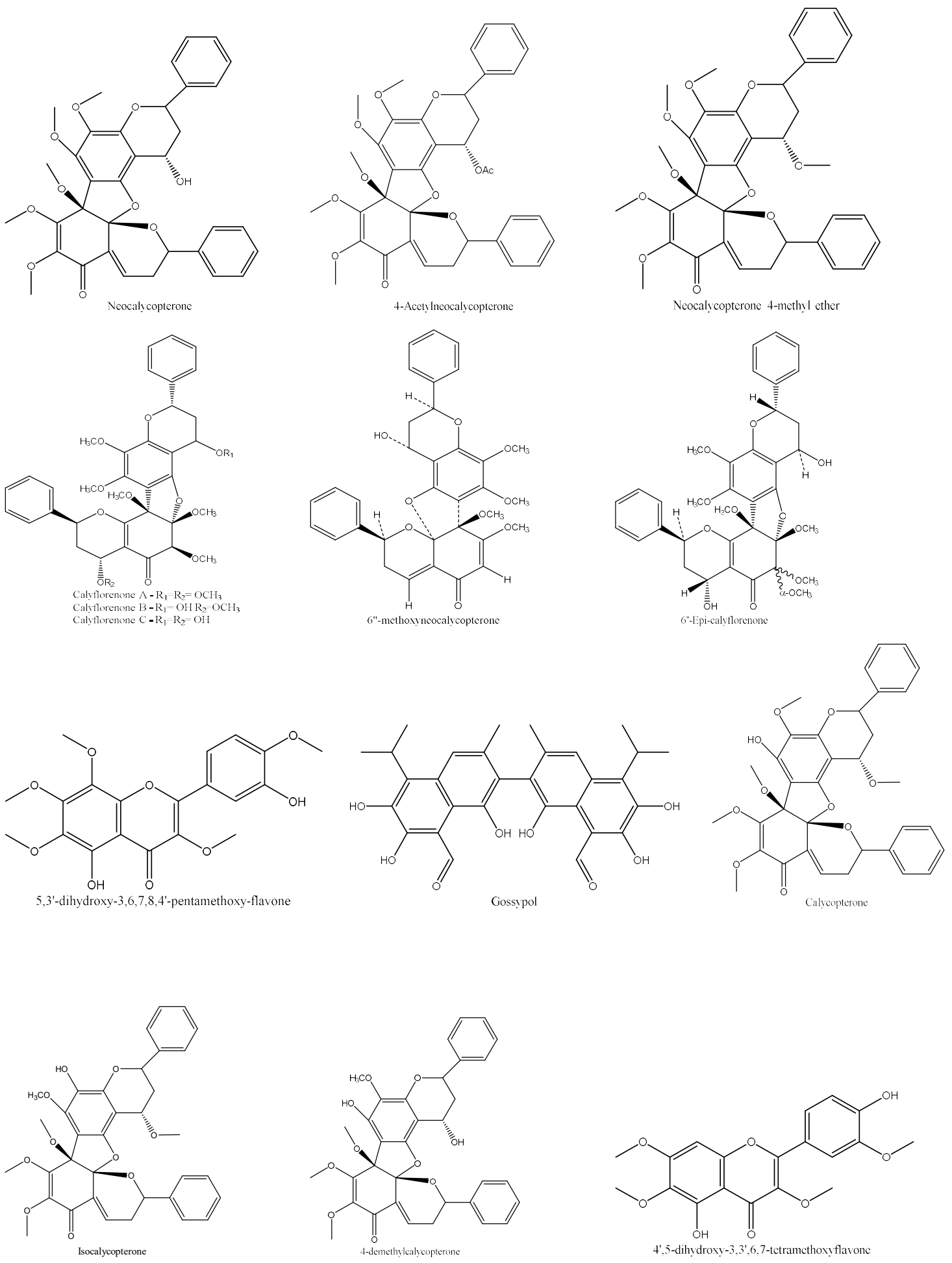


\section{The optimized protocol [18]}

$$
\begin{array}{ll}
\text { Method } & : \text { High Performance Liquid Chromatography } \\
\text { Column } & : \text { Lichrospher C18 } \\
\text { Mobile phase } & : \text { Acetonitrile and ultrapure water }(3: 1) \\
\text { Detector } & : \text { UV detector } \\
\text { Wavelength } & : 365 \mathrm{~nm} \\
\text { Injected Vol. } & : 1.0 \mathrm{~mL} \mathrm{~min} \\
\text { Temperature } & : 35^{\circ} \mathrm{C}
\end{array}
$$

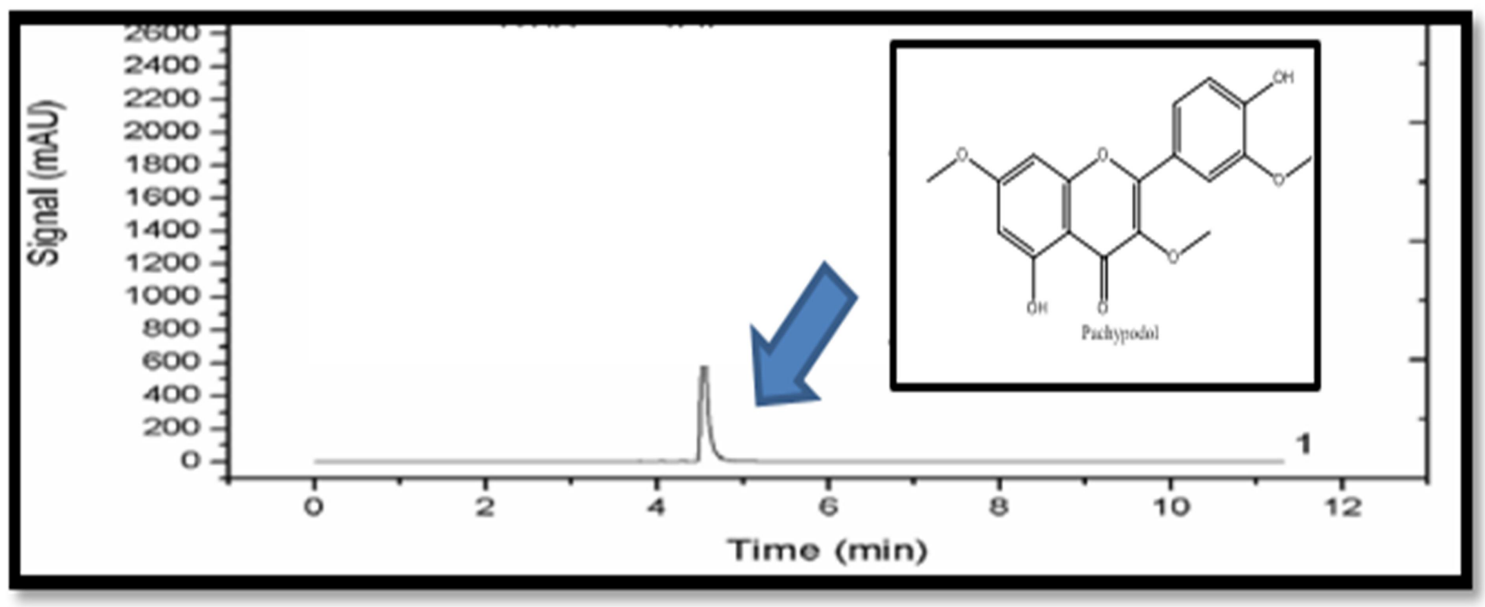

Figure 13: HPLC Quantification of Pachypodol (Arrowhead) [18]

\section{BIOLOGICAL STANDARDIZATION}

The biological potential of Calycopteris floribunda plant is widely established. The plant Calycopteris floribunda is host to a large number of flavonoids. There are numerous reports on the antimicrobial and antioxidant activity studies for the plant extracts.

\section{Antimicrobial Activity}

The various solvent extracts of Calycopteris floribunda earlier screened for antibacterial activity are reported to exhibit good inhibition of test bacteria. The earlier reports and present work on antibacterial and antifungal activity are summarised in Tables 11 and 12. 
Table 11: Antibacterial Activity of Solvent Extracts of Calycopteris floribunda [7, 9, 10, 23, 30, 35]

\begin{tabular}{|c|c|c|c|c|c|c|c|c|c|c|c|c|c|c|}
\hline \multirow[b]{2}{*}{ S. No } & \multirow[b]{2}{*}{ Crude / Extracts } & \multicolumn{13}{|c|}{ Bacterial Strains with Zone of Inhibition (mm) } \\
\hline & & $\mathbf{a}$ & $\mathbf{b}$ & c & d & e & f & $\mathbf{g}$ & $\mathbf{h}$ & i & $\mathbf{j}$ & $\mathbf{k}$ & I & $\mathbf{m}$ \\
\hline 1. & Petroleum ether & 6 & -- & 21 & 21 & -- & -- & -- & -- & -- & 21 & 20 & 1 & 2 \\
\hline 2. & $\begin{array}{l}\text { Hexane } \\
\text { (Present Work) }\end{array}$ & -- & -- & 5 & 18 & -- & 7 & -- & -- & -- & -- & 10 & -- & -- \\
\hline 3. & Chloroform & 4 & -- & 24 & 22 & -- & -- & -- & -- & -- & 23 & 19 & 2 & 1 \\
\hline 4. & Ethyl acetate & 6 & -- & -- & -- & -- & -- & -- & -- & -- & 4 & -- & 4 & 1 \\
\hline 5. & Diethyl ether - Methanol & 18 & -- & 21 & -- & -- & -- & -- & -- & -- & -- & 19 & -- & -- \\
\hline 6. & Pet ether-Butanol & 14 & -- & 16 & -- & -- & - & -- & -- & -- & -- & 16 & -- & - \\
\hline 7. & $\mathrm{CH}_{2} \mathrm{Cl}_{2}: \mathrm{MeOH}$ & 21 & 19 & 19 & 14 & 14 & 19 & - & -- & -- & -- & -- & -- & -- \\
\hline 8. & 1-Butanol & 15 & 16 & 16 & 16 & 15 & 14 & - & -- & -- & -- & -- & -- & -- \\
\hline 9. & Methanol & 8 & -- & 16 & 14 & -- & -- & 10 & 11 & 14 & 09 & 18 & 4 & 2 \\
\hline 10. & Aqueous 90\% MeOH & 18 & 18 & 23 & 16 & 16 & 23 & -- & -- & -- & -- & 13 & -- & - \\
\hline 11. & $\begin{array}{l}\text { Hydroethanol (90\% Ethanol) } \\
\text { (Present Work) }\end{array}$ & -- & -- & 22 & 20 & -- & 20 & - & -- & -- & -- & 10 & -- & -- \\
\hline 12. & Aqueous & -- & -- & 15 & 12 & -- & -- & 09 & 11 & 14 & 08 & -- & -- & -- \\
\hline
\end{tabular}

a- Bacillus subtilis; b-Streptococcus pyogen; c-Staphylococcus aureus; $\mathrm{d}-$ Escherichia coli; $\mathrm{e}-$ Pseudomonas aerogenes; $\mathrm{f}-$ Salmonella typhi; $\mathrm{g}-$ Salmonella typhimurium ;

h-Klebsiella pneumoniae; i-Clostridium perfringens; j-Pseudomonas aeruginosa; k-Bacillus cereus; l-Actinomycetes sp.; m-Seratia sp

Table 12: Antifungal activity of Calycopteris floribunda

\begin{tabular}{|c|c|c|c|c|c|c|c|}
\hline & & \multicolumn{5}{|c|}{ Zone of Inhibition (mm) [31] } \\
\cline { 3 - 7 } S. No & Extracts & $\begin{array}{c}\text { Microsporium } \\
\text { gypsium }\end{array}$ & $\begin{array}{c}\text { Chrysosporium } \\
\text { keratinophilum }\end{array}$ & $\begin{array}{c}\text { Trichophytum } \\
\text { rubrum }\end{array}$ & $\begin{array}{c}\text { Chrysosporium } \\
\text { indicum }\end{array}$ & $\begin{array}{c}\text { Fusarium } \\
\text { oxysporum }\end{array}$ & $\begin{array}{c}\text { Pythium } \\
\text { aphanidermatum }\end{array}$ \\
\hline 1 & Methanol & 10 & 12 & 14 & -- & - \\
\hline 2 & Aqueous & 12 & 14 & 12 & 10 & 22 & \\
\hline
\end{tabular}


Antioxidant Activity

The antioxidant activity was studied by various assays. The results of DPPH free radical scavenging assay, total antioxidant activity (phosphomolybdic acid method), ferric reducing antioxidant potential (FRAP) assay, superoxide anion radical scavenging, hydroxyl radical and lipid peroxidation assay are reported in Table 13.

\section{Other Activity Studies}

There are numerous reports validating the antimicrobial, antioxidant potential of the various parts of Calycopteris floribunda. However, there are very few reports on other activity studies. Much of the studies on pharmacological potential of Calycopteris floribunda is done with leaf extracts. The leaf acetone extract is reported to possess anthelminthic activity [11]. The butanol extract of the leaves is found to inhibit $\beta$ glucuronidase (80\% inhibition) [10]. The leaf extract has been also tested for hypoglycemic effect [37]. The stem extract of this plant is reported to exhibit anti-inflammatory [36] and hepatoprotective potential [38].
Apart from the extracts of this plant, some of the compounds isolated are also tested for medicinal potential. Table 14 lists the compounds tested and their medicinal potential.

\section{Toxicity Studies}

So far, there are two reports of toxicity studies on this plant Calycopteris floribunda. The fresh leaves of Calycopteris floribunda were found to be hepatotoxic, nephrotoxic, and cardiotoxic in calves; its methanol extract was found to be toxic at $400 \mathrm{mg} / \mathrm{g}$ body weights of rats and rabbits [27]. This study reveals that the plants and its parts might be toxic for oral intake. However, its immense medicinal potential indicates that this plant may be recommended as an ingredient of topical ointments and thailams. Acute toxicity studies and dermal toxicity studies have not been reported. Yet another report of general toxicity studies reveal that the flavonoid pachypodol isolated from the leaves has $\mathrm{LD}_{50}$ of $435.8 \mathrm{M}$ [17].

Table 13: Antioxidant Activity Studies on Calycopteris floribunda [8, 10, 23,]

\begin{tabular}{|c|c|c|c|}
\hline S. No. & Assay & Name of extract & Scavenging Activity $(\%)$ or $(\% \pm$ SM $)$ \\
\hline \multirow[t]{7}{*}{1} & \multirow[t]{7}{*}{ DPPH radical scavenging assay } & Diethyl ether-Methanol & 56 \\
\hline & & Petroleum ether- Butanol & 88 \\
\hline & & DCM-МeOH & 66 \\
\hline & & Aq. $90 \% \mathrm{MeOH}$ & 89 \\
\hline & & 1-Butanol & 92 \\
\hline & & Chloroform & $65.33 \pm 1.38$ \\
\hline & & Methanol & $72.5 \pm 1.17$ \\
\hline \multirow[t]{3}{*}{2} & \multirow[t]{3}{*}{ FRAP assay } & Petroleum ether & $37.52 \pm 0.041$ \\
\hline & & Ethyl acetate & $78.82 \pm 0.013$ \\
\hline & & Methanol & $67.56 \pm 0.086$ \\
\hline \multirow[t]{3}{*}{3} & \multirow[t]{3}{*}{ Total antioxidant activity } & Petroleum ether & $50.79 \pm 0.021$ \\
\hline & & Ethyl acetate & $76.53 \pm 0.040$ \\
\hline & & Methanol & $69.67 \pm 0.034$ \\
\hline \multirow[t]{2}{*}{4} & \multirow{2}{*}{$\begin{array}{c}\text { Superoxide anion radical } \\
\text { scavenging assay }\end{array}$} & Chloroform & $52.4 \pm 1.7$ \\
\hline & & Methanol & $70.8 \pm 0.95$ \\
\hline \multirow[t]{2}{*}{5} & \multirow{2}{*}{ Hydroxyl radical scavenging assay } & Chloroform & $53.83 \pm 1.29$ \\
\hline & & Methanol & $60.9 \pm 0.50$ \\
\hline \multirow[t]{2}{*}{6} & \multirow{2}{*}{$\begin{array}{c}\text { Lipid peroxidation scavenging } \\
\text { assay }\end{array}$} & Chloroform & $58.06 \pm 0.63$ \\
\hline & & Methanol & $52.20 \pm 1.04$ \\
\hline
\end{tabular}




\begin{tabular}{|c|c|c|}
\hline Compound & Source & Medicinal Potential \\
\hline Calycopterin [11] & Leaves & Anthelminthic activity \\
\hline $\begin{array}{l}\text { 3'-amino-5-hydroxy-3,6,7,8,4'-pentamethoxy } \\
\text { flavone }[21]\end{array}$ & Leaves & Antiproliferative activity \\
\hline $\begin{array}{l}\text { Calycopterone [22] } \\
\end{array}$ & \multirow[t]{3}{*}{ Flowers } & \multirow{3}{*}{$\begin{array}{c}\text { Anti-cancer activity against } \\
\text { Frederick-NCI human tumour cancer } \\
\text { cell lines }\end{array}$} \\
\hline Isocalycopterone [22] & & \\
\hline 4-demethylcalycopterone [22] & & \\
\hline Pachypodol [17] & Leaves & $\begin{array}{c}\text { Anti-cancer activity against } \mathrm{CaCo-2} \\
\text { colon cancer cell lines } \\
\left(\mathrm{IC}_{\mathbf{5 0}}=\mathbf{1 8 5 . 6} \mu \mathrm{M}\right)\end{array}$ \\
\hline
\end{tabular}

\section{CONCLUSION}

This review consolidates all the available scientific data on Calycopteris floribunda which is an important ayurvedic medicinal plant. It finds use as one of the constituents of the Ayurvedic formulation named "Jathyadi Thailam" used as a wound healing medicine in Ayurveda treatment. The plant is found to be a rich source of flavonoidal compounds. Of all the compounds isolated, only one compound named pachypodol has been quantified from leaf extracts. The highly medicinal flavonoid quercetin is also reported from this plant. However, this compound has not been quantified. The rich antioxidant potential of the plant may be bestowed upon it by the presence of its flavonoidal constituents. There are recent reports on the use of the crushed roots of Calycopteris floribunda as an oral antidote for snake bite [39]. Also the juice from the leaves are taken internally to cure dysentery [40]. An interesting observation reports use of an oral medication of leaves to cure manganese deficiency [26]. Deficiency of manganese leads to poor bone growth or skeletal defects. Hence, the plant may be considered as a source for manganese supplementation.
All available data on the plant Calycopteris floribunda, as well as the findings of this study, are documented as a ready reckoner sheet, which will assist herbal manufacturers who use this plant in developing standardized formulations. This will aid in increasing the validity of the product labels, thereby increasing the global market value of formulations containing Calycopteris floribunda.

\section{ACKNOWLEDGEMENT}

The authors acknowledge Avinashilingam Institute for Home Science and Higher Education for Women for providing facilities and AVP Pvt. Ltd. Coimbatore for generous contribution of authenticate leaves of Calycopteris floribunda.

\section{CONFLICT OF INTEREST}

The authors declare no Conflict of Interest.

\section{REFERENCES}

[1] Selvan K, Yoganandam P, Gopal V, Standardization of traditional medicine need and urgency, International Journal of Phytotherapy, 2013, 3, 5-10.

[2] Badgujar SB, Patil MB, Ethnomedicines for jaundice used in tribal areas of North Maharashtra, 
Natural Product Radiance, 2008, 7(1), 79-81.

[3] Nikam PH, Kareparamban, J, Jadhav A, Kadam V, Future trends in standardization of herbal drugs, Journal of Applied Pharmaceutical Science, 2012, 2(6), $38-44$

[4] Ekka NR, Namdeo KP, Samal PK, Standardization strategies for herbal drugs-An overview, Research Journal of Pharmacy and Technology, 2008, 1(4), 310-312.

[5] Rajani M, Kanaki NS, Phytochemical standardization of herbal drugs and polyherbal formulations, Bioactive molecules and medicinal plants, 2008, 349369.

[6] Yusuf M, Choudhury JU, Wahab MA, Begum J, Medicinal Plants of Bangladesh. Bangladesh Council of Scientific and Industrial Research, Dhaka, Bangladesh, 1994, 1-340.

[7] Glory A, Judin J, Vasudevan R, Sumathi P, Prelimanary phytochemical content and antibacterial activity of Ukshi (Calycopteris floribunda Lam.) leaves, Journal of Medicinal Plants Studies, 2016, 4(2), 57-59.

[8] Santharam B, Ganesh P, Soranam R, Divya VV, Lekshmi NCJP, Evaluation of in vitro free radical scavenging potential of various extracts of whole plant of Calycopteris floribunda (Lam.), Journal of Chemical and Pharmaceutical Research, 2015, $7(1), 860-864$.

[9] Vinayaka KS, Rajakumar N, Kekuda TRP, Roopashree AC, Comparative Antibacterial Efficacy of Methanol and Aqueous Extracts of Calycopteris floribunda (Roxb.) Poiret, Advances in Plant Sciences, 2011, 24(1), 39-41.

[10] Dey SK, Shoeb M, Rob T, Nilafar N, Mosihuzzaman M, Sultana N, Biological and chemical studies of Calycopteris floribunda leaves, The Dhaka University Journal of Pharmaceutical Sciences, 2005, 4(2), 1816-1839.

[11] Ratnagiriswaran AN, Sehra KB, Venkataraman K, The anthelminthic constituent of the leaves of Calycopteris floribunda, Biochemical Journal, 1934, 28, 1964-1967.

[12] Shah RC, Virkar VV, Venkataraman K, The constitution Journal of the Indian Chemical Society of calycopterin, the yellow coloring matter of the leaves of Calycopteris floribunda, Journal of the Indian Chemical Society, 1942, 19, 135-38. 
[13] Khorana ML, Motiwala DK.

Anthelmintics, Isolation of

Calycopteris floribunda, Indian

Journal of Pharmacol, 1948, 10, 98-99.

[14] Gupta SR, Seshadri TR, Sood GR, Flavonols and Other Compounds of The Leaves of Calycopteris floribunda, Phytochemistry, 1973, 12(10), 2539-2540.

[15] Muhamed KS, Neelakantan S, Raman PV, Chemical components of Indian medicinal plants (Thespesia populnea wood and Calycopteris floribunda Current Science flowers), Current Science, $1975,44,888-889$.

[16] Rao AVR, Varadan M, Calycopeterin 4'-methyl ether and 3'-methoxycalycopterin in the leaves of Calycopteris floribunda, Indian Journal of Chemistry, 1973, 11, 403-404.

[17] Ali HA, Chowdhury AA, Rahman AK, Borkowski T, Nahar L, Sarker SD, Pachypodol, a flavonol from the leaves of Calycopteris floribunda, inhibits the growth of $\mathrm{CaCO}_{2}$ colon cancer cell line in vitro. Phytotherapy Research. 2008, 22(12), 1684-1687.

[18] Liu X, Yang DL, Liu JJ, Xu K, Wu $\mathrm{GH}$, Modeling of supercritical fluid extraction of flavonoids from
Calycopteris floribunda leaves, Chemical Papers, 2014, 68(3), 31623.

[19] Mayer R, Calycopterones and Calyflorenones, Novel Biflavonoids from Calycopteris floribunda, Journal of Natural Products, 1999, 62(9), 1274-1278.

[20] Mayer R, Five biflavonoids from Calycopteris

floribunda

(Combretaceae), Phytochemistry, 2004, 65(5), 593-601.

[21] Lewin G, Shridhar NB, Aubert G, Thoret S, Dubois J, Cresteil T, Synthesis of antiproliferative flavones from Calycopterin, major flavonoid of Calycopteris floribunda Lamk, Bioorganic and Medicinal Chemistry, 2011, 19(1), 186-196.

[22] Wall ME, Wani MC, Fullas F, Oswald JB, Brown DM, Santisuk T, Reutrakul V, McPhail AT, Farnsworth NR, Plant Antitumor Agents. The Calycopterones, a New Class of Biflavonoids with Novel Cytotoxicity in a Diverse Panel of Humn Tumor Cell Lines, Journal of Medicinal Chemistry, 1994, 37(10), 1465-1470.

[23] Bhat PR, Prajna PS, Kumar V, Hegde MA, Singh L, Antimicrobial properties of leaves of Calycopteris floribunda Lam, 
Journal of Medicinal Plants

Research, 2011, 5(12), 2448-2451.

[24] Saha A, Rahman MS, Antimicrobial activity of crude extract from Calycopteris floribunda. Bangladesh Journal of Microbiology, 2008, 25(2), 137139.

[25] Kirthikar KR, Basu BD, Indian Medicinal Plants. Oriental Enterprises: Uttaranchal, India, 2001, 5, 1441-1443.

[26] Kulal C, Padhi RK, Venkatraj K, Satpathy KK, Mallaya SH, Study on Trace Elements Concentration in Medicinal Plants Using EDXRF Technique, Biological Trace Elements Research, 2020, 198(1), $1-10$

[27] Sreekanth P, Narayana K, Shridhar NB, Bhat A, Toxicity studies of Calycopteris floribunda Lam. in calf, rabbit and rat, Journal of Ethnopharmacology, 2006, 107(2), 229-233.

[28] Bijauliya RK, Alok S, Chanchal DK, Kumar M, A comprehensive review on standardization of herbal drugs, International Journal of Pharmaceutical Science and Research, 2017, 8, 3663-3677.

[29] Rajput KS, Patil VS, Rao KS, Development of included phloem of Calycopteris floribunda Lamk.
(Combretaceae), The Journal of the

Torrey Botanical Society, 2009, 136(3), 302-312.

[30] Pavithra GM, Abhishiktha S. Naik, Siddiqua S, Vinayaka KS, Kekuda PTR, Mukunda S, Antioxidant and antibacterial activity of flowers of Calycopteris floribunda (Roxb.) Poiret, Humbpldtia brunonis Wall and Kydia Calycina Roxb., International Journal of Drug Development and Research, 2013; 5(2): 99-102.

[31] Vinayaka KS, Kekuda TRP, Shivakumar B, Shravanakumara S, Anti-dermatophyte activity of methanol and aqueous extracts of Calycopteris floribunda (Roxb.) poiret leaves, Natural Products: An Indian Journal, 2009, 5, 215-219.

[32] Satyanarayana T, Eswaraiah MC, In vitro antioxidant and free radical scavenging potential of stem of Calycopteris floribunda Lam., Research Journal of Pharmaceutical Biological and Chemical Sciences, 2010, 1(2), 117-123.

[33] Vantamuri AB, Sounshi YB, Kotresh O, Dodamani S, A Preliminary study on total phenolic content and antioxidant activities of Calycopteris floribunda Root extracts, International Journal of 
Pharmaceutical Sciences and

Research. 2018, 9(7), 3020-3023.

[34] Kumar KAR, Pavithra GM, Junaid S, Rakesh KN, Dileep N, Siddiqua S, Abhishiktha S. Naik, Kekuda TRP, Vinayaka KS, Elemental analysis and anticariogenic activity of flowers of Calycopteris floribunda, Humboldtia brunonis and Kydia calycina, Asian Journal of Research in Chemistry, 2013, 6(7), 623-627.

[35] Jia-Jia L, Dong-liang Y, Yan Z, Yao Y, Fu-xiang C, Jian-ming Z, Xiao-bo P, Chemical component and antimicrobial activity of volatile oil of Calycopteris floribunda, Journal of Central South University Technology, 2009, 16(6), 931-935.

[36] Satyanarayana T, Eswaraiah MC, Bharathi A, Srinivas M, Anti inflammatory activity of stem of Calycopteris floribunda. Journal of Pharmacy and Chemistry, 2009, $3(2), 57-59$.

[37] Thalla S, Tammu J, Delhiraj N, Kumar KS, Hypoglycemic Activity of Hydro-alcoholic Extract of Calycopteris floribunda Induced by Streptozotocin in Rats, International Journal of Pharmaceutical Sciences and Drug Research, 2012, 4(4), 250-252.
[38] Eswaraiah MC, Satyanarayana T, Hepatoprotective activity of extracts from stem of Calycopteris floribunda Lam. against carbon tetrachloride induced toxicity in rats, International Journal of Pharmacognosy and Phytochemical Research, 2010, 2(3), 53-57.

[39] Kuvar SD, Shinde RD, Plants used by kokni tribe as antidote for snake bite and scorpion sting from Nasik and Dhule districts of Maharashtra, Journal of Global Biosciences, 2019, 8(3), 6043-6050.

[40] Natarajan B, Paulsen BS, An ethnopharmacological study from Thane district, Maharashtra, India: Traditional knowledge compared with modern biological science, Pharmaceutical Biology, 2000, 38(2), 139-51. 